\title{
Os indígenas da Reserva Caramuru-Paraguassu: famílias étnicas e organização política
}

\author{
Jurema Machado de Andrade Souza \\ Universidade Federal do Recôncavo da Bahia - UFRB \\ e-mail: juma.machado.souza@gmail.com
}

\begin{abstract}
Resumo
O artigo busca demonstrar os arranjos étnicos concernentes à coletividade autodenominada Pataxó Hãhãhãi, que se localiza na Reserva Indígena CaramuruParaguassu, no sul da Bahia, considerando suas implicações políticas e territoriais. Do mesmo modo, procura discutir de que maneira as distintas percepções sobre as histórias de cada grupo/família e etnia - categorias que veremos reunidas em torno do conceito de famílias étnicas - produziram uma narrativa de luta que possibilitou a retomada integral do território indígena ao longo das três últimas décadas.
\end{abstract}

Palavras-chave: pataxó, famílias étnicas, território.

\begin{abstract}
This article focuses on the ethnic arrangements established by the Indigenous group known as Pataxó Hãhãhãi, -which inhabits the reservation Caramuru-Paraguassu, in the south part of the state of Bahia, Brazil-, analyzing their political and territorial implications. It also considers how the different perceptions regarding the history of each family/group and ethnie -categories that converge to the concept of ethnical familieshave produced a narrative about the territorial struggle that has alowed the Pataxó Hãhãhãi to completely recuperate their territory along the past three decades.
\end{abstract}

Keywords: pataxó, ethnical families, territory.

Os Pataxó Hãhãhãi, que habitam o sul da Bahia, mais especificamente, a Reserva Indígena Caramuru-Paraguassu ${ }^{1}$, estão organizados em unidades designadas famílias étnicas (Baenã, Kariri-Sapuyá, Kamacã, Gueren, Tupinambá e Hãhãhãi), ao abrigo do denominado parentesco de sangue. Este, por sua vez, concerne a três níveis ou categorias classificatórias crescentes, ou seja, aos membros da família de procriação ou parentes consanguíneos; àqueles componentes de uma determinada "família étnica" ou povo; e, finalmente, ao conjunto formado pelas várias famílias étnicas, que se identificam mutuamente como parentes. (CARVALHO \& SOUZA,

\footnotetext{
${ }^{1}$ Inicialmente criada como Reserva Caramuru-Catarina Paraguassu, a atual Terra Indígena Caramuru-Paraguassu passou a ser referida deste modo durante o processo de regularização fundiária. Entretanto, farei a opção de citála aqui como Reserva Indígena Caramuru-Paraguassu, que é a maneira como os indígenas a designam, em função de considerarem preeminente que terras lhe tenham sido reservadas no passado, o que lhes geraria um direito inconteste em tempos atuais.
} 
2000). Esses grupos distintos também estão referidos a seus troncos velhos, como são chamados os antepassados. Por continuidade, os indígenas chamam os grupos específicos de troncos, mas também simplesmente famílias ou etnias. Esses etnônimos são operativos em âmbito local, através da associação entre família e lugar (lugar de origem ou de estabelecimento na reserva), como, por exemplo, Família dos Kariri-Sapuyá de Pedra Branca, Família dos Kamacã de Catolezinho e assim sucessivamente.

A ênfase nativa nas identidades específicas faz referência não apenas às distintas origens, mas também às trajetórias vividas na dispersão a que os indígenas foram violentamente compelidos, quando os laços étnicos e familiares, postos à prova, revelaram seu vigor (SOUZA, 2012). A decisão pela adoção de um etnônimo englobante remete a um momento decisivo de sua história recente, a retomada da Fazenda São Lucas no ano de 1982, quando teve início o longo esforço conjunto pela recuperação do território tradicional, que só chegaria a bom termo 30 anos depois.

Os dados etnográficos e as reflexões apresentadas aqui são fruto de uma relação de pesquisa de 18 anos entre mim e o povo Pataxó Hãhãhãi, bem como do diálogo com colegas no âmbito do Programa de Pesquisas sobre Povos Indígenas do Nordeste Brasileiro - PINEB/UFBA e do Laboratório e Grupo de Estudos em Relações Interétnicas - LAGERI/UnB. Ao longo desses anos, realizei pesquisas acadêmicas (graduação, mestrado, doutorado, trabalhos de pesquisa e extensão), e também atuei como indigenista da Associação Nacional de Ação Indigenista - ANAI/BA, o que me permitiu um longo e contínuo acompanhamento da luta para a recuperação do território, e das dinâmicas identitárias dos indígenas da Reserva CaramuruParaguassu.

Em 1926, o Serviço de Proteção aos Índios (SPI) criou a Reserva CaramuruCatarina Paraguassu, em terras cedidas pelo Estado da Bahia, para "gozo dos índios Pataxós e Tupinambás" (Lei Estadual n 1916/1926)2. A criação da reserva, que hoje abarca 54.000 hectares dos municípios de Pau-Brasil, Itaju do Colônia e Camacã, objetivava conter os indígenas que ainda se encontravam nas matas do sul da Bahia. Posteriormente, outros povos, outrora localizados em missões e aldeamentos extintos, também foram conduzidos para a área. Contemporaneamente, a reserva, em sua totalidade, passou a ser constituída pelo etnônimo englobante Pataxó Hãhãhãi, compreendendo as etnias Baenã, Pataxó Hãhãhãi, Kamacã, Tupinambá, Gueren e Kariri-Sapuyá.

\footnotetext{
2 Estado da Bahia. Diário Oficial. Salvador, 11/08/1926. Pp. 9935. Grifo meu.
} 
A partir da década de 1930, as terras da referida reserva começam a ser alvo da cobiça de grandes fazendeiros, ao mesmo tempo em que pequenos lotes nas suas margens começam a ser arrendados a não índios pelo próprio SPI. Após sérias e violentas investidas, a quase totalidade das terras da reserva foi invadida, o que culminou na expulsão da ampla maioria dos indígenas. Entre as décadas de 1970 e 1980, o governo do estado da Bahia concedeu títulos de propriedade de terras aos invasores da reserva, com a justificativa de que ali "não havia mais índios, só meia dúzia de descendentes no posto abandonado de Itajú do Colônia" ${ }^{3}$. Mobilizado a partir do final dos anos de 1970, um grupo de indígenas aciona a Fundação Nacional do Índio (FUNAI) e organizações de apoio à causa indígena. Em 1982, dão início à ocupação contemporânea das terras da reserva, à retomada de antigos etnônimos, de memória das aldeias de origem e das distintas trajetórias de cada grupo étnico.

Como assinala Hugo Prudente Pedreira, no que diz respeito "à ênfase no pertencimento às famílias, o reconhecimento dos troncos velhos como ancestrais e a persistência das diferenças de sangue", o sangue apresenta ambivalência na produção do parentesco (PEDREIRA, 2017, p. 17). Em contrapartida, ele é o elemento definidor do que é ser parente, "parente mesmo", "parente próximo". Por outro lado, entendo que o sangue que produz o parentesco mais amplo, acentuado em uma expressão muito usual ("somos todos parentes"), é o sangue derramado na luta, o sangue das ações para a reconquista do território, já que "a luta se faz com sangue", o sangue dos antepassados, o sangue dos que tombaram em épocas recentes, que constituem os ícones da história recente dos Pataxó Hãhãhãi, como Galdino, João Cravinho, Samado, Bahetá. E, quando se trata dessa questão, não há contestação ou acento na diferença: o etnônimo englobante Pataxó Hãhãhãi, impulsionado na retomada da Fazenda São Lucas, produz aquilo que eles chamam de povo. "Um povo se faz na luta", como eles dizem...

As experiências negativas que todos os indígenas da Reserva Indígena Caramuru-Paraguassu compartilharam não parecem haver aplacado o sentimento de pertencimento a esse espaço, antes ocorrendo o contrário. Afinal, os seus mortos estão lá, muitos dos seus filhos lá nasceram e continuam nascendo, uniões conjugais foram lá constituídas e, eventualmente, desfeitas, assim como amizades. As identidades foram lá forjadas e a vida de cada um constitui um feixe de lembranças positivas e negativas que não podem ser esquecidas, sob pena de resultar um vazio existencial. Por tudo isso, as noções locais de luta e de compromisso com a

\footnotetext{
3 Depoimento de Maura Titia, india Baenã, sobre a resposta que lhe foi dada pelos representantes do governo,
} quando questionados sobre a ilegalidade da distribuição dos títulos numa área demarcada para reserva indígena. 
comunidade são tão valorizadas. Quem não lutou pela reconquista do território invadido demonstra não ter apreço pela comunidade, não sendo, pois, digno de ali continuar se reproduzindo, biológica e socialmente. Em outros termos, quem não tem experiências de retomada para relatar não faz jus à identidade indígena e ao usufruto do território.

Por outro lado, a luta empreendida e o compromisso com a comunidade seja a englobante, seja a de pertencimento primário - não eliminam a percepção da mistura. Embora se reconheçam, em conjunto, como parentes de sangue, os indígenas acionam também o sangue para assinalar as diferenças internas. Admitem como algo inapelável a mistura, ao mesmo tempo em que afirmam que, desde a retomada de 1982, o etnônimo Hãhãhãi prepondera sobre essas diferenças de sangue. Um jovem pode justificar que é hãhãhãi (e não baenã, tupinambá ou kamacã) por que é "misturado" (pertence a mais de uma família étnica) ou por que nasceu depois de 1982, o que leva à conclusão de que mistura é um termo que traduz valores complementares e/ou antagônicos. Recentemente, no âmbito do recadastramento para atendimento à saúde, um dos agentes encarregados da atividade, ao preencher a sua ficha individual, no quesito etnia, assinalou "Pataxó Hãhãhãi", no que foi interpelado por um dos conselheiros de saúde, que o instou a definir a sua etnia, já que o seu pai é Baenã e a sua mãe, KaririSapuyá. O jovem prontamente contra-argumentou que poderia se identificar simplesmente como Pataxó Hãhãhãi, "que significa povo misturado". O assunto foi, naquele momento, encerrado. Vale notar, por último, que o jovem em questão nasceu em 1987, já no contexto da emergência étnica Pataxó Hãhãhãi.

Quando indagados sobre o assunto, os indígenas não admitem a existência de regra explícita para alianças matrimoniais no interior dos diversos grupos étnicos que se distribuem pela área da reserva e entre os mesmos. Entretanto, pode-se observar a realização de arranjos familiares entre as chamadas famílias étnicas, o que aponta para a inter-relação entre parentesco e identidade, através da ênfase no etnônimo de cada família ("Eu sou da família dos Kariri-Sapuyá de Pedra Branca", ou "fulano é do povo de Itaju") e, em alguns casos, em "nomes trazidos do mato" incorporados como sobrenomes nos descendentes. São os casos dos nomes da índia Bute e do índio Titiah: ambos foram capturados pelas frentes de atração e tiveram seus nomes registrados pelo próprio SPI, que se encarregou de registrar seus filhos do mesmo modo (por exemplo, José Bute ou Batará Bute). 0 sobrenome Bute, inclusive, é de uma pequena família de classe média da cidade de Itabuna (os sete filhos de José Bute e seus descentes), em que 
todos os membros conhecem sua ascendência indígena, mas só duas pessoas mantêm relação com os parentes do posto 4 .

Enquanto aguardavam a decisão da justiça na ação de nulidade dos títulos de propriedade emitidos sobre a reserva, os Pataxó Hãhãhãi retornavam paulatinamente ao território. Alguns agrupamentos, como parcela dos Kariri-Sapuyá e Tupinambá, encontravam-se em cidades ou vilarejos próximos à reserva, ao passo que outros, como os Kamacã e alguns membros Baenã, estavam em Minas Gerais e São Paulo. A retomada da Fazenda São Lucas, a primeira a ocorrer, em 1982, foi liderada por dois líderes Kariri-Sapuyá, uma líder Baenã e um líder Tupinambá. Após o sucesso da ação, cada um encarregou-se de noticiar a seus parentes, através de cartas, que haviam "entrado na terra". Após esse restabelecimento, durante os atos de retomada territorial, prevaleciam as relações internas entre as diversas etnias, ou seja, uma certa demarcação de fronteiras étnicas, como estamos vendo.

O sucessivo processo de retomadas, que tomou mais fôlego a partir do final de 1999, obedeceu a estratégias em torno da unificação dos distintos grupamentos étnicos, ou seja, foi levado a cabo por membros de todas as etnias estabelecidas na reserva. As circunstâncias sociais e políticas reinantes no período determinaram, como mecanismo de resistência mais oportuno, a tentativa de unificar os grupos em função de seu objetivo comum, que era expandir a ocupação e o controle do território. Essa estratégia era acionada e girava em torno das figuras de cacique e vicecacique, e do quadro de lideranças, procurando-se contemplar cada etnia, através da escolha de seus respectivos representantes para compor uma espécie de conselho ampliado, consultivo e deliberativo. Após efetuada cada retomada, mediante a retirada dos denominados proprietários e funcionários da fazenda, prosseguia-se com a ocupação pelos indígenas, mediante a migração de famílias para a nova área.

Essas ocupações tinham caráter coletivo, e qualquer família podia construir casas e passar a residir ali, se assim desejassem e se suas intenções fossem acolhidas pelo referido conselho ampliado. Os recursos naturais poderiam ser igualmente explorados por todos, tais como plantações de cacau, árvores frutíferas, currais e pastos.

Pouco depois, as estratégias de retomada passaram a observar uma lógica diferente, própria a cada agrupamento étnico. Atribuo essa alteração ao fato de ter ocorrido o rompimento de alianças políticas estratégicas entre as

\footnotetext{
${ }^{4}$ Para maior análise sobre produção de parentesco, e sobre os significados de sangue e mistura entre os Pataxó Hãhãhãi, ver PEDREIRA (2017).
} 
duas famílias étnicas hegemônicas (no sentido de detentoras de maior força política e controle sobre os recursos humanos e materiais), a saber, os Kariri-Sapuyá e os Tupinambá. A partir de então, o cenário se altera: os Baenã, usualmente mais ligados politicamente aos Kariri-Sapuyá, passaram a efetuar retomadas próprias, que alternavam com o seu afastamento do cenário político; os Kamacã, por sua vez, sentindo-se negligenciados, também procuraram retomar seus locais de origem, ainda que sempre em aliança com os Kariri-Sapuyá, muito possivelmente em função de alguns casamentos existentes entre essas duas famílias étnicas. Todos esses processos procuravam remeter cada família aos lugares de moradia tradicionais, ou seja, da época de seu estabelecimento na reserva pelo SPI. Outro fator que ensejou essa ação mais voltada a cada agrupamento foi provocada pela elaboração de um mapa onde se plotou os locais de moradia dos mais velhos, dos troncos. O coordenador da Funai à época, visando reforçar o pleito junto ao STF, reuniu uma noite, embaixo de uma cabana, os velhos de todas as famílias. Acompanhados de professores e lideranças de suas respectivas famílias, esses velhos apontaram as localizações das posses recebidas quando da chegada à reserva e referiam os nomes de cada região: Mundo Novo, Toucinho, Serra da Bananeira, Rancho Queimado, Panelão, Alegrias, Braço da Dúvida, Entra com jeito. Esse mapa, produzido a partir do próprio mapa da Funai, foi distribuído posteriormente para representantes de cada família.

Como mencionado, em 1982, os Pataxó Hãhãhãi, representados naquele momento por membros das famílias étnicas, retomaram uma área de 1.200 hectares - a Fazenda São Lucas -, simbolicamente localizada na região do Mundo Novo, sede do posto indígena Paraguassu. Desde então, os distintos contingentes étnicos vêm se distribuindo por áreas mais ou menos distintas, que, em certos casos até o presente, funcionam, prática ou afetivamente, como áreas de pertencimento étnico.

O laudo elaborado por Aracy Lopes da Silva e Nassaro Násser - solicitado pelo juiz federal Lázaro Guimarães, após conceder liminar ao Interdito Proibitório interposto pela FUNAI para assegurar a permanência dos indígenas na reserva - privilegiou a elaboração de genealogias das distintas famílias consanguíneas, para corroborar os vínculos de parentesco que uniam as gerações de indígenas moradores daquele território, desde sua constituição, em 1926. Nesse laudo, Lopes da Silva e Nasser constataram que as etnias estabelecidas na reserva se encontravam interpenetradas, não obstante compartilhassem um forte sentimento de pertencimento aos respectivos grupos e lugares de origem (NÁSSER \& LOPES DA SILVA, 1984). 
É importante notar que esse traço, a coesão, pode ser detectado no levantamento genealógico, mediante a recorrência de casamentos entre primos cruzados, ou seja, uniões entre filhos de irmãos de sexos opostos, e a reiteração de relações de aliança entre determinadas famílias, através de casamentos sucessivos... (Ibid.).

Nasser e Lopes da Silva chamavam atenção para esse fato em 1984, tomando como referência o relatório da historiadora Maria Hilda Baqueiro Paraíso, de 1976: "Finalmente, salientamos que cada facção tem seu núcleo centralizado na sua etnia específica o que, por sua vez, corresponderia aos vários grupos domésticos nucleares nos diferentes pontos da Reserva, e fora dela. Outro aspecto a ser destacado é a cessão que chega a extrapolar os limites da família nuclear. Os vínculos ultrapassam as unidades familiares e abrangem o grupo maior composto pelos grupos familiares que têm a mesma origem étnica, ou mais simplesmente, geográfica e que se definem como Hãhãhãi, 'índios de Santa Rosa', 'índios de Olivença'. Formavam assim, 3 grandes grupos extremamente coesos internamente, mas parcialmente autônomos entre si" (PARAÍsO, 1976, p. 49). Portanto, Paraíso identificou à época apenas " 3 grandes grupos", dois dos quais referidos apenas aos locais de origem que, ao longo do tempo - e, provavelmente, em decorrência do retorno gradativo dos indígenas dispersos -, se ampliariam para os atuais cinco grupos.

Isso quer dizer que parece ter ocorrido um movimento que, sem anular as referências toponímicas, teria feito emergir, com certa força, etnônimos correspondentes aos locais de origem, mediante as várias relações sociais estabelecidas com antropólogos, agências laicas e confessionais, além da própria FUNAI.

Teriam surgido, assim, o que designo famílias étnicas, isto é, famílias genealógica e etnicamente definidas que se reportam aos antepassados referidos como troncos velhos 5 . Os chamados troncos velhos, por sua vez, constituem o suporte que distingue cada família étnica em relação às outras. A ênfase nessas identidades específicas, sob a forma de famílias étnicas, está também reportada às trajetórias vividas na diáspora, "quando

\footnotetext{
${ }^{5}$ Entre 1999 e 2000, durante meu trabalho de campo ainda para a monografia de conclusão do bacharelado em Ciências Sociais junto à Universidade Federal da Bahia (UFBA), os Kariri-Sapuyá Gerson Souza Melo e Ilza Rodrigues esforçaram-se para me fazer compreender o que seria a organização social que utiliza etnônimo englobante, mas que aciona a ênfase em etnias por famílias ou famílias por etnias para marcar ações de luta como as retomadas, que ocorriam naquele período. A partir dessas conversas, cheguei àquilo que convencionei chamar de "famílias étnicas". Trata-se de um termo não nativo, mas cujo entendimento só é possível através das categorias nativas de família/etnia, sangue e mistura. Para o entendimento das categorias de sangue e mistura entre os Pataxó Hãhãhãi, ver PEDREIRA (2017).
} 
os laços étnicos e familiares, postos à prova, revelaram o seu vigor (SOUZA, 2012).

A força dos etnônimos é algo bastante contemporâneo, tanto assim que tem sido objeto de muitas controvérsias e disputas, que são regularmente alimentadas. Como também já destaquei, a sua diferenciação interna sempre se fez apelando para os locais de origem, isto é, Pedra Branca/Santa Rosa (Kariri-Sapuyá), Olivença (Tupinambá), Catolezinho (Kamacã)m São Fidelis (Gueren) e Serra do Couro Dantas (Baenã e Hãhãhãi).

Cada local de origem reporta-se a um tronco velho e a uma "história diferente", ao passo que a convivência colaborou para a produção, na Reserva Caramuru-Paragussu, de uma única pretendida história. $\mathrm{Na}$ diáspora, novos esquemas mentais, e novas disposições corporais e morais foram adquiridos, obliterando, em larga medida, os hábitos tradicionais, 0 que tende a requerer lapso de tempo considerável para a sua reconversão, nos planos de cada coletivo étnico e no da comunidade supraétnica ou Pataxó Hãhãhãi. Vale notar que, a rigor, duas diásporas são identificadas pelos indígenas: a primeira, experimentada pelos ascendentes mais velhos, expulsos dos aldeamentos, e a segunda, quando seus pais e avós foram compelidos a se retirar de suas posses na reserva.

Carolina Almeida, analisando o caso Terena, nos apresenta uma interessante relação entre troncos/ancestralidade, mas também troncos/pessoas. "'Tronco' (Xuve), para os Terena, faz referência às lideranças políticas e domésticas, como também ao grupo de indivíduos unidos por relações de parentesco e amizade que residem próximos uns aos outros, em geral, partilhando das mesmas atividades econômicas. Igualmente, Xuxe é associado na linguagem corrente à ideia geral de ascendência e ancestralidade" (ALMEIDA, 2016, p. 2). Entre os Pataxó Hãhãhãi, é muito comum Bahetá, Lucília Muniz, Samado Santos, Jacinta, Thithiá e Itático serem acionados como os troncos velhos, que já partiram - marcando, assim, pessoa, ascendência e ancestralidade em uma mesma chave analítica -, mas que não necessariamente deixaram descendência filial, como é o caso de Bahetá. A sua descêndencia é, pois, da resistência, em que resistir é entendido como continuar vivendo não obstante todas as agruras e infortúnios, mas também como se fazer na luta. Ou seja, as famílias e indivíduos que reivindicam Bahetá como "tronco" o fazem em função de ela ser considerada como "do mato", o que lhe confere um grande potencial de ancestralidade, mas não de ascendência, e por sua intensa participação na permanência constante na área do antigo posto Caramuru, mesmo durante o grande período de dispersão das várias famílias. 
Nesse sentido, podemos nos reportar mais uma vez ao caso Terena, na medida em que o Xuve (tronco) "é o grupo familiar/comunitário e as figuras responsáveis por ele. Ele é um coletivo investido de qualidades pessoais concretizadas na figura do (in)divíduo (o casal) tronco. Ele é o chefe investido de qualidades coletivas concretizadas no seu Ovokuti. Ele é também toda a história e a memória que encarna. Ele é, enfim, o processo fluído e dinâmico que o constitui. Pessoa coletiva, coletivo personalizado, o tronco é raiz e é semente" (ibid., p. 4)

Os indígenas da Reserva Caramuru-Paraguassu entendem e interpretam as diferenças étnicas vigentes na área através da "história de cada povo", pois "cada povo que tem aqui tem uma história diferente, de antes... mas depois passou a ter uma história só porque todo mundo vive aqui agora". Quando relatam suas trajetórias, referem-se aos distintos lugares onde haviam nascido e morado, e destacam os locais de origem de seus troncos velhos, a exemplo de Pedra Branca (Kariri-Sapuyá), Olivença (Tupinambá) e Catolezinho (Kamacã). A geração que está na faixa etária entre 25 e 30 anos, na sua maioria, não nasceu na área da Reserva Indígena CaramuruParaguassu, ou na "área do Posto Indígena", como eles costumam designar. As gerações anteriores a essa (40-50 e 60-70 anos) nasceram na reserva, mas moraram em outros lugares, fora da área indígena, em decorrência da dispersão à qual foi compelida a grande maioria dos Pataxó Hãhãhãi, em meados da década de 1950 e 1960.

Como já mencionado, os indígenas registram duas dispersões: a primeira, sofrida por seus antepassados expulsos dos aldeamentos onde estavam estabelecidos antes do deslocamento para a Reserva Indígena CaramuruParaguassu e a segunda, quando seus pais e avós foram obrigados a entregar suas terras, sob a pressão do governo, através do SPI, e de regionais, que afirmavam que os indígenas "não teriam mais nada ali, [que] todas as terras do posto estavam arrendadas e [que] o governo não se responsabilizaria mais por eles", que, doravante, era "cada um por si". Essa segunda dispersão compulsória é mais reiterada em suas narrativas, facultando o conhecimento de seus variados locais de nascimento e moradia antes do retorno para a reserva, a partir da primeira retomada.

Aliás, em muitas situações, esse retorno não ocorreu no mesmo período. Em alguns casos, os pais e filhos mais velhos retornaram primeiro, para estabelecer contato com as lideranças que haviam encabeçado a reconquista, pois, segundo eles, era necessário saber o número de membros da família nuclear e reconhecer os parentes, que haviam perdido contato durante a dispersão. Muitos relembram o momento da sua chegada, quando 
encontravam, na corrente ${ }^{6}$, o cacique da época, Nelson Saracura, que procedia à "checagem de quem era índio mesmo", de quem tinha saído dali anos antes ou de seus descendentes.

É importante assinalar que Nelson Saracura, Kariri-Sapuyá de Pedra Branca, apesar de cacique, não foi o único responsável pela admissão das pessoas no retorno à reserva. Outros líderes, de etnias diferentes, como o Tupinambá Nailton Muniz, por exemplo, também efetuaram o "reconhecimento do seu povo". Os fatores para a admissão eram, basicamente, a ancestralidade da família e de seus membros, a partir da memória dos mais velhos, das referências aos locais de moradia (Toucinho, Serra da Bananeira, Mundo Novo etc.), bem como, e não menos importante, dos laços que haviam sido estabelecidos em décadas passadas. Ou seja, era importante ser reconhecido por outro índio, morador do mesmo local, como tendo sido residente na área do posto, e também era fundamental a disposição para a luta pela terra.

Como vimos, o reconhecimento de distintas trajetórias, decorrentes da primeira e da segunda dispersões, impedem a apreensão dos Pataxó Hãhãhãi como uma unidade, embora, em muitos âmbitos, eles se percebam como uma totalidade. Melhor dizendo, na esfera privada, do cotidiano da reserva, as diferenças são notadas com muita presteza. Arrisco-me a supor que subjaz à identidade global Pataxó Hãhãhãi a clara percepção de que eles são um povo com origens distintas, com diferenças marcantes, que, nos dias de hoje, são objetivadas e sentidas nos planos da organização social, geográfica e política. Certa vez, a cacique Ilza, comentou: "a diferença tá no povo todo, a gente é uma nação, nação indígena, mas que dentro dela tem as diferenças de sangue, de famílias...".

Talvez possamos nos aproximar, aqui, da ideia de comunidades imaginadas de Benedict Anderson. Segundo esse autor, as comunidades imaginadas (nações) se formam a partir de estilos culturais próprios, capazes de produzir metáforas e outros símbolos exclusivos. O que há de comum em todas elas é a utilização simbólica do parentesco - "somos todos parentes" -, como o exemplo da metáfora da Mãe-Pátria, ou no caso, indígena, a MãeTerra (ANDERSON, 2008).

Os Pataxó Hãhãhãi parecem reconhecer que a diáspora a que foram compelidos ensejou diferenças entre as famílias, e mesmo internamente a cada uma delas, mas admitem também que a posterior reunião, a partir da

\footnotetext{
${ }^{6}$ O local referido como "corrente" é a entrada da antiga Fazenda São Lucas, onde, de fato, havia uma corrente presa entre duas estacas de cerca. Com o tempo a corrente quebrou ou perdeu o uso, mas o local continua a ser assim designado.
} 
década de 1980, na antiga reserva, teria possibilitado o estreitamento dos vínculos, tornando-os um povo. Não devemos supor, todavia, que existe inquestionável coesão interna entre as famílias. As tensões políticas se fazem sentir também no interior das famílias étnicas, quando os interesses conflitam. Atualmente, por exemplo, existem dois caciques (um homem e uma mulher) que são membros de uma mesma família.

Uma firme e altiva senhora Kariri-Sapuyá, que mantém uma delicada relação com os encantados, o que a faz reputada como uma grande rezadeira, não se intimida em afirmar que a família étnica que está estabelecida na aldeia como Kamacã, não o é. Segundo ela, essa classificação lhe foi atribuída em 1982, por antropólogos que visitaram a área no período. Quando repliquei que essa família também retornou em 1982, pois era efetivamente moradora do posto em épocas passadas, ela respondeu que o patriarca, já falecido, pai da atual matriarca Kamacã, era posseiro, funcionário do SPI. A sua reação deve ser contrabalançada, uma vez que os velhos Kariri-Sapuyá se caracterizam por um marcante etnocentrismo, que, na prática, reverbera em um sentimento de indianidade, fenotípica e histórica, pronunciada: segundo essa perspectiva, são eles os verdadeiros indígenas, a medida a ser considerada em relação aos demais. Quem não é Kariri-Sapuyá, quem não foi conduzido por Curt Nimuendajú na década de 1930 para a área do posto, não tem sua identidade indígena corroborada por eles ${ }^{7}$. A sua condescendência apenas se volta aos descendentes dos chamados "índios do mato", daqueles capturados pelas frentes de atração do SPI, os filhos e netos de Titiah, Ketão, Onrak.

Já em relação aos Tupinambá, as divergências não são interpretadas como questionamentos de sua indianidade, mas a partir de distinções políticas, decorrentes de condutas divergentes na maneira de conduzir a luta ${ }^{8} \mathrm{e}$ em relação à forma de viver. Essas questões, segundo uma professora, provocam rivalidades entre as crianças, na escola indígena, e dificultam o trabalho dos professores. Essa observação serve como indício de que a escola reproduz as contradições e diferenças internas, seja no conteúdo didático, seja no difícil relacionamento entre alunos de etnias diferentes.

Umas das grandes questões discutidas da escola indígena é como conciliar a história das distintas famílias étnicas com o conteúdo programático anual e com a disposição individual dos professores. Ou seja, uma professora

\footnotetext{
${ }^{7}$ Nimuendaju observou que os Kariri-Sapuyá teriam desenvolvido, "apesar do cruzamento", um forte sentimento de raça, dividindo a humanidade em duas partes: (1) "Nós índios", seja qual for a descendência; e (2) "os contrários", ou o resto da humanidade (NIMUENDAJU apud CARVALHO E SOUZA, 2000).

${ }^{8}$ De acordo com a acepção utilizada por Max Weber, para quem "Uma relação social denomina-se luta quando as ações se orientam pelo propósito de impor a própria vontade contra a resistência do ou dos parceiros... Somente falaremos de "luta" quando efetivamente existe uma situação de concorrência. (...) (WEBER 1991, p. 23-24).
} 
tupinambá, por exemplo, manifesta claramente que não se sente à vontade para ensinar aos seus alunos kariri-Sapuyá sobre "a saga dos índios de Pedra Branca". Contudo, os professores escudam-se em uma retórica que procura minimizar os efeitos da diversidade étnica e que considera que, se a história os compeliu a compartilhar um mesmo território, isso ocorreu há já algum tempo e, portanto, urge minimizar as diferenças. Nesse tipo de racionalização, os Pataxó Hãhãhãi são um só um povo, ocupam um território de 54 mil hectares e a história dos antepassados não deve acentuar as diferenças étnicas. A própria interlocutora, que se autoidentifica internamente como Kariri-Sapuyá e conhece a trajetória histórica dos "índios da Pedra Branca", já tendo, inclusive, visitado a área de estabelecimento da antiga aldeia, na porção sul do Recôncavo baiano, quando se apresenta em contextos externos ou assina documentos, é Margarida Pataxó.

Outra senhora Kariri-Sapuyá, que é casada com um primo, reforça a diferença: "nós somos tudo um parente só, uma gente só e os outros não é parente. Os outros [outros indígenas de dentro da reserva] são estranhos. Tem que casar com parente por causo que fica com o sangue limpo. E com outros o sangue não é limpo". E completa: "família somos nós assim, tudo um sangue só. O mesmo parente...".

Certa vez, fui até sua casa, atendendo a um convite, pois ela havia confeccionado um colar para mim, a título de presente. Ao lá chegar, ela exibiu mais dois colares, um para seu marido usar em uma viagem a Brasília e um segundo, que seria usado por ela no casamento do cunhado, irmão do marido. Perguntei sobre esse casamento, quem eram os noivos, e ela me relatou a insatisfação da família de seu marido, sogra e cunhados, com essa nova união. A jovem pretendente do cunhado é Kamacã, e, apesar dos laços de amizade entre eles, a família do marido não aceitava a união, sob o argumento de que a moça era de uma "nação diferente", não tinha o "sangue puro", em face do que vaticinava que a união não daria certo.

A mãe alertou o filho que, se ele insistisse em casar, não edificasse casa perto da sua, que fosse estabelecer moradia onde residem os Kamacã. Problematizei o caráter do impedimento, já que a moça era índia, ao que a minha interlocutura, prontamente, retrucou: "A diferença é por causa que da mesma etnia tudo que um quer, o outro quer... Aí quando tem 3 um puxa pra um lado, outro puxa pra outro e não dá certo nada. É por isso que nós tamo aqui tudo misturado e não tá dando nada certo... Nunca endireita, só vive assim...". 
Os Kamacã sentem-se discriminados pelos demais. Eles alegam que são o povo que mais tem parentes fora da reserva ${ }^{9}$, o que atribuem aos óbices interpostos pelos líderes das demais famílias étnicas. A sua rarefação demográfica tem consequências importantes: é interpretada como impossibilitando a ocupação de porções da reserva entendidas como suas, onde seus antepassados haveriam nascido e vivido. A emergência dos Gueren, ligados aos Kamacã por vínculos incontestes de parentesco, enfrenta a mesma resistência de afirmação étnica e circulação pelas terras da reserva. Não obstante, em que pese as restrições demonstradas quanto à indianidade dos Kamacã e Gueren, eles estabelecem alianças políticas estratégicas com os Kariri-Sapuyá.

Os homens e mulheres da reserva costumam atribuir às distinções étnicas as dificuldades experimentadas para se organizar social, cultural e politicamente. Percebe-se, portanto, uma certa tendência à segmentação interna, cada família étnica se retraindo em relação às demais. Enquanto os indígenas aguardavam o resultado do julgamento da ação de nulidade, o projeto político coletivo dizia respeito à retomada integral do território, após cuja conquista as famílias étnicas iriam, gradativamente, definindo suas fronteiras e "vivendo cada um do seu jeito, com sua cultura". Isso parece querer dizer que a cultura, ao tempo em que aproxima, afasta, seja em decorrência de incompatibilidades estruturais, seja de experiências históricas particulares (como aqueles resultantes das diásporas a que eles foram submetidos) ou, finalmente, mediante a exacerbação de certos itens e/ou instituições, deliberadamente acionados para produzir diferença e afastamento culturais, em um contexto interétnico complexo.

As dinâmicas identitárias dos indígenas da Reserva Caramuru-Paraguassu estão referidas mutuamente a dois planos: aquele que remete a uma identidade interna, de oposição aos outros grupos residentes na reserva, e aquele que diz respeito a uma outra identidade, de caráter mais geral, englobante da variedade das etnias, acionada com o propósito de estabelecer diferenciação entre índios e não índios. Enquanto no primeiro plano a distinção étnica interna define a organização espacial dentro da reserva, no segundo, a identidade englobante, através do etnônimo Pataxó Hãhãhãi, é fator fundamental para garantir a manutenção do território indígena e "marcar suas fronteiras" em relação ao Estado-nação. Cabe salientar que um plano não se sobrepõe ao outro em uma relação de subordinação, já que a inter-relação entre ambos só é passível de ser compreendida se a entendemos através de relação de homologias. Ou seja,

\footnotetext{
${ }^{9}$ Referem que seus parentes estão em Teixeira de Freitas, Jacarecy, Itabuna, Belo Horizonte e na cidade de São Paulo.
} 
- acionamento dessas identidades acontece de forma associada a contextos mais amplos, sendo que a atualização histórica não anula o sentimento de referência à origem.

Como enfatizado Fredrik Barth (2000), as fronteiras e manutenção destas mostrou rapidamente que os grupos étnicos são produzidos sob circunstâncias interativas, históricas, econômicas e políticas particulares. No caso da Reserva Caramuru-Paraguassu cada um dos grupos étnicos é, pelos agentes, e por mim, como observadora, apreendido como uma "família", isto é, família genealógica e etnicamente definida.

Finalmente, podemos afirmar que a escassez da terra e a desterritorialização imputaram a esses indígenas novos reordenamentos de ocupação a partir de novas alianças e denominações étnicas. Eles permanecem em constante dinâmica de reorganização social e política, em função, principalmente, do retorno de novas famílias.

Recentemente, em meu trabalho de campo para o doutorado, percebi que a tensão em torno das chamadas origens e etnias estava ficando ainda mais evidente. Na época, ocorria o recadastramento para o atendimento à saúde. Os agentes de saúde, todos indígenas, saíam de casa em casa preenchendo uma ficha relativa ao grupo doméstico e outra relativa a cada indivíduo morador. Tanto na ficha do domicílio, quanto na ficha individual, havia um campo relativo à etnia. Após o recadastramento de toda a reserva, as fichas foram analisadas pelos conselheiros de saúde e caciques. Fichas em que uma família ou indivíduo respondiam somente "Pataxó" ou "Pataxó Hãhãhãi" recebiam do referido conselho uma interrogação. Marcava-se com a família dias depois para que pudessem comparecer a uma reunião com o dito conselho, onde se inquiria sobre a origem, os troncos velhos daquela família. Se nada pudesse ser dito, ou se nada pudesse ser comprovado perante outras famílias, recomendava-se que fossem investigar seus troncos, sua etnia. Para tanto, caciques e lideranças os orientavam a procurar antropólogos que conhecessem os indígenas dalí. Esse mecanismo de reconhecer os parentes é muito informado por aquele utilizado pelo SPI, quando uma família indígena ganhava posse na reserva mediante relato acerca de que aldeia (extinta, na maior parte das vezes) havia saído. Complementarmente, a ênfase nos etnônimos decorre, especialmente, da relação estabelecida com antropólogos e organizações indigenistas a partir do final dos anos de 1970.

As evidências parecem significar que as diferenças, sobretudo étnicas, não forjam fronteiras rígidas. Na prática, elas são removidas ou acentuadas quando as circunstâncias assim o aconselham, do mesmo modo que as 
contradições são contornadas, quando daí possam resultar benefícios recíprocos. Muitas vezes, não obstante os preconceitos e etnocentrismos mútuos, subsistem profundos vínculos entre essas etnias, especialmente entre as suas gerações mais velhas, cujo núcleo é o reconhecimento de um passado comum na reserva.

Nesse sentido, o passado continua provendo sentidos adequados para compreender, e suportar novas situações - passado pleno de sofrimentos, humilhações e coerções, que, todavia, tem seu papel na criação de "comunidades morais", a demonstrar, como afirma Veena Das, que a violência não gera apenas destruição (DAS, 1995).

\section{Referências Bibliográficas}

ALMEIDA, Carolina Perini. O vivido como topologia: terra, corpo e tradição a partir de experiências terena em se relacionar com seus parentes e seus lugares. Apresentação no Seminário Contra-antropologias da Terra 2016, PPGAS/UnB. Mimeo. 2016.

ANDERSON, Benedict. Comunidades imaginadas. Reflexões sobre a origem e a difusão do nacionalismo. São Paulo: Companhia das Letras, 2008.

BARTH, Fredrik. O guru, o iniciador e outras variações antropológicas. Rio de Janeiro: Contra Capa. 2000.

CARVALHO, Maria Rosário \& SOUZA, Jurema Machado de A. "Raça, Gênero e Classe em perspectiva comparativa: nordeste do Brasil e Amazônia ocidental". In: Anais do I Simpósio Internacional O Desafio da Diferença: articulando gênero, raça e classe. Salvador: UFBA, 2000.

CARVALHO, Maria Rosário \& SOUZA, Jurema Machado de A. Verbete Pataxó Hãhãhãi. Enciclopédia dos Povos Indígenas. www.socioambiental.org.br

DAS, Veena. Critical Events: An Anthropological Perspective on Contemporary India. New Delhi: Oxford University Press, 1995.

NÁSSER, Nássaro N. \& SILVA, Ma. Aracy Lopes da. Laudo Antropológico Interdito Proibitório 32.096, 2a. Vara da Justiça Federal -Salvador-BA, 1984

PARAÍSO, Maria Hilda. "Relatório Sobre a História e Situação da Reserva dos Postos Indígenas "Caramuru e Catarina Paraguassu" apresentado à Fundação Nacional do Índio". Convênio FUNAI-UFBA. Salvador, 1976.

PEDREIRA, Hugo Prudente. Os Pataxó Hãhãhãe e o problema da diferença. Dissertação apresentada ao Programa de Pós-Graduação em Antropologia 
Social da Faculadde de Filosofia, Letras e Ciências Humanas da Universidade de Sâo Paulo, 2017.

SOUZA, Jurema Machado de A. Trajetórias Femininas Indígenas: Gênero, memória, identidade e reprodução. Dissertação apresentada ao Programa de Pós-Graduação em Ciências Sociais/Antropologia da Faculdade de Filosofia e Ciências Humanas da Universidade Federal da Bahia, 2007.

Parentesco e Organização Social na Reserva CaramuruParaguassu, sul da Bahia. Anais da 28a Reunião Brasileira de Antropologia. São Paulo, 2012.

WEBER, Max. Economia e Sociedade. Vol. I. Brasília: Editora Universidade de Brasília, 1991. 